\title{
Avaliação da cobertura do solo e métodos de irrigação na produção de melancia
}

\section{Soil covers and irrigation in the production of watermelon}

\author{
Joaquim Alves de Lima Junior ${ }^{1}$; Paulo Roberto de Andrade Lopes ${ }^{2 *}$
}

\section{Resumo}

O presente trabalho foi conduzido no setor de horticultura da Universidade Federal Rural da Amazônia (UFRA) em Belém-PA, no período de 15 de agosto de 2004 a 16 de janeiro de 2005. Objetivouse avaliar o efeito da cobertura solo e diferentes métodos de irrigação na produção de melancia no delineamento blocos ao acaso em esquema fatorial 4 x 3, com três repetições, sendo utilizada a cultivar pérola com 10 plantas por parcela. Foram utilizados três tipos de cobertura de solo (filme de polietileno de baixa densidade de dupla face; fibra de coco e palhada) e dois métodos de irrigação (localizada tipo gotejamento e superfície tipo sulco). Obteve-se um relativo aumento na produção da melancia com o uso do gotejamento na variável de numero de frutos com uso da irrigação por gotejamento e sulco. A utilização do gotejamento proporcionou peso médio de frutos superior em torno de $6,24 \mathrm{~kg}$ e diâmetro logitudinal e transversal de frutos de $24,34 \mathrm{~cm}$ e $22,44 \mathrm{~cm}$, respectivamente. Verificou-se que as coberturas fibra de coco e palhada proporcionaram medias maiores para número de frutos de 11,77 e 9,66 , respectivamente. Observou-se, ainda, que não houve diferença no diâmetro longitudinal de fruto com o uso das diferentes coberturas testadas neste trabalho.

Palavras-chave: Citrullus lanatus, plasticultura, produção

\begin{abstract}
The present work was carried out in the section of horticulture of the Universidade Federal Rural da Amazônia (UFRA) in Belém-PA, in the period from August 15, 2004 to January 16, 2005. The aim was to evaluate the effect of soil covering and different irrigation methods on the yield of the watermelon. The experimental design was blocks at random in a 4 × 3 factorial outline, with four replications and 10 plants per parcel. Three soil covering were used, film of polyethylene of low density and couple face; coconut fiber; and straw. The irrigation methods used were localized (drip) and surface (furrow). It was obtained an increase in the number of fruits with irrigation. The utilization of the drip irrigation provided a medium fruit weight of $6.24 \mathrm{~kg}$ and diameter of 24.34 and $22.44 \mathrm{~cm}$ (longitudinal and transversal). Coconut fiber and straw covering provided greater measures to the number of fruits , around 11.77 and 9.66 , respectively. It was also observed that there was no difference on the longitudinal diameter of the fruit with the use of the different coverings.
\end{abstract}

Key words: Citrullus lanatus, plasticulture, crop

1 Mestrando-UFLA-Departamento de Engenharia Agrícola-Lavras-MG-CEP-7200-000.

2 Prof. Dr. Adjunto IV- Instituto de Ciências Agrárias da UFRA-AV. Presidente Tancredo Neves, 2501, CEP: 66.077-530, BelémPA

* Autor para correspondência 


\section{Introdução}

No caso especifico da cultura da melancia (Citrullus lanatus thunb Mansf) tem-se observado nos últimos anos um incremento na exploração comercial dessa cucurbitácea. No Brasil, os principais centros de produção são os estados do Rio Grande do Sul, Bahia, Maranhão, São Paulo, Piauí, Goiás e Pernambuco (AZEVEDO, 2005).

Segundo Martins et al. (1998), a interação estabelecida entre planta, ambiente e práticas fitotécnicas, condicionam respostas fisiológicas e agronômicas, não só do ponto de vista quantitativo (rendimento), como também qualitativo (características organolépticas e nutricionais). Essas características, segundo os mesmos autores, são afetadas pelo manejo da água, cobertura do solo, práticas de tutoramento e poda, entre outros.

A deficiência de água no solo afeta praticamente todos os aspectos relacionados ao crescimento das plantas, reduzindo a área foliar, diminuindo a fotossíntese e afetando outros processos fisiológicos (BERGAMASCHI et al, 1992). Além disso, a água é um dos fatores determinantes para a produção, e por isso a sua falta ou excesso influenciam diretamente a produtividade da cultura, tornando indispensável a escolha do método de irrigação e o seu manejo racional para se conseguir a maximização da produção (REICHARDT, 1978).

Para o cultivo da melancia, a irrigação por gotejamento proporciona níveis de umidades ideais na zona das raízes durante todo o ciclo da cultura, o que é importante para desenvolvimento de plantas exigentes em água (VIEIRA; MANFRINATO, 1974). Devido a menores variações na umidade do solo, os frutos, em geral, desenvolvem-se melhor e são mais uniformes. Isso também pode ser obtido com os outros métodos de irrigação, desde que se use um menor turno de rega (BERNARDO, 1984).

Como alternativa para o pequeno produtor, o sistema localizado (xiquexique) é um dos mais indicados, por permitir o melhor controle da quantidade de água no colo da planta e evitar a formação de microclimas úmidos, que favorecem, sobretudo, o aparecimento de doenças fúngicas e bacterianos (CARVALHO, 1999).

Em contraste com outros métodos, a irrigação por sulco não umedece toda a superfície do solo, pois, normalmente atinge uma faixa úmida de $30 \%$ a $80 \%$ da superfície total, diminuindo assim as perdas por evaporação, reduzindo a formação de crosta na superfície dos solos argilosos e tornando possível cultivar o solo e realizar colheitas, logo após as irrigações, o que não ocorre com outros métodos, exceto o gotejamento (BERNARDO, 1984).

A cobertura do solo é uma técnica que vem sendo aplicada há muitos anos pelos agricultores que utilizavam principalmente resíduos de palha, capim ou serragem para dar proteção aos cultivos. Com o passar do tempo esses resíduos, tornaram-se escassos nas propriedades rurais necessitando, desta forma, mais mão-de-obra para sua aplicação.

A forma mais viável economicamente de substituição destes materiais para proteger o solo com cobertura morta só foi possível com o emprego de filmes plásticos, os quais, além de suprir o conhecido problema dos agricultores, possibilitam a obtenção de novas e importantes vantagens. As coberturas plásticas afetam o microclima do solo pela alteração no saldo de radiação da superfície e por evitar a evaporação de água do solo (LIAKATAS; CLARK; MONTEITH, 1986). Tais fatores podem afetar a temperatura e a umidade do solo na zona das raízes e, consequentemente, o desenvolvimento vegetativo e a produtividade das plantas.

Araújo (2000) comparou para a cultura de melão, entre vários métodos de cobertura, o filme de polietileno dupla face prateado e o solo descoberto, observando que essa cobertura não apresentou diferença significativa para número, peso médio e produtividade de frutos comerciáveis do híbrido Gold Mine. Nas culturas de melão e melancia, Ininov (1997) e Bhella (1988), respectivamente, verificaram que coberturas com polietileno transparente e preto, proporcionaram incrementos 
no crescimento das culturas, produção total de frutos, quando comparadas com a testemunha. Martins (1983) avaliou o efeito de diferentes coberturas de solo, plástica (transparente, azul translúcido e preto), orgânica (cascas de arroz, acícula de Pinus e maravalha), sobre o rendimento produtivo do morangueiro, em comparação ao solo descoberto, em Viamão, RS. Não foram observadas diferenças significativas entre as produções obtidas nas coberturas plásticas, quando comparadas ao solo descoberto, embora tenha sido observada uma tendência de maior produção nas coberturas plásticas. Grewal e Singh (1974) citado por Muller (1991) avaliaram o efeito da cobertura com material orgânico sobre o regime hídrico do solo em comparação com filme de polietileno e solo descoberto. Os autores observaram que a umidade do solo foi semelhante em todos os tratamentos, mas a necessidade de irrigação foi menor no solo com cobertura plástica, devido à cobertura plástica evitar a transferência da água para atmosfera, seguido da cobertura orgânica e da condição sem cobertura, sendo que essa duas situações anteriores permitem a transferência de água para a atmosfera.

O objetivo desta pesquisa é avaliar o efeito da cobertura solo e diferentes métodos de irrigação na produção da melancia.

\section{Material e Métodos}

O experimento foi realizado no Campus da Universidade Federal Rural da Amazônia - UFRA, no setor de horticultura do Instituto de Ciências Agrárias (ICA) - localizado no município de BelémPA. O solo utilizado no experimento é caracterizado como Latossolo Amarelo, de textura média. Utilizou-se a cultivar Pérola, de origem japonesa e caracterizada por possuir frutos arredondados. As mudas foram formadas em bandejas com 128 células e utilizando o substrato comercial plantmax ${ }^{\circledR}$. O experimento foi implantado no delineamento de blocos casualizados, no esquema fatorial quatro (cobertura do solo) x três (método de irrigação), com três repetições, totalizando 36 parcelas. A parcela experimental constituiu-se de uma fileira dupla com 10 plantas, com $2 \mathrm{~m}$ de largura por 13,5 $\mathrm{m}$ de comprimento. Foram utilizadas as seis plantas centrais de cada linha da fileira dupla do meio como plantas úteis totalizando 10 plantas por parcela.

O preparo da área consistiu de aração, gradagem cruzada, sulcamento, estercamento, adubação de plantio e de cobertura durante a condução do experimento segundo a analise química de solo.

Para cobertura do solo foram utilizados os seguintes tratamentos: filme de polietileno de baixa densidade de dupla face com uma face de coloração preta e outra face leitosa, sendo esta face exposta a radiações colocadas ao redor das plantas com uma área de $1 \mathrm{~m}^{2}$ nas respectivas parcelas; a segunda cobertura implantada foi à fibra grossa de coco (casca - resíduo do processamento dos frutos); a terceira cobertura foi a palhada formada de gramíneas diversas sendo estas duas ultimas cobertura colocadas sobre a linha dupla da parcela e também tiveram as parcelas sem cobertura do solo que serviram de testemunha. Como método de irrigação foi utilizado o sistema de irrigação localizado tipo gotejamento e o sistema de irrigação por superfície tipo sulco, e houve também a utilização de parcelas sem irrigação que serviram como testemunha.

Para controlar os níveis de irrigação por gotejamento, foramutilizadostensiômetros, enquanto a irrigação por sulco foi estimado o tempo de 60 minutos diários relativo à curva de característica do solo para elevar a umidade a capacidade de campo. As irrigações por gotejamento foram realizadas toda vez que o tensiômetro indicava tensões próximas da critica em torno de 30 a $80 \mathrm{kPa}$, de acordo com o recomendado por Doorenbos e Pruitt (1977) para a maioria das curcubitaceas.

As mudas de melancia foram plantadas no espaçamento de $2,0 \mathrm{~m}$ entre linhas e $1,5 \mathrm{~m}$ entre plantas,consistindo de filas duplas. Após a colheita foram avaliadas as características: número de frutos, peso médio de frutos, diâmetro longitudinal e transversal de frutos. 
A obtenção da análise de variância pelo teste $\mathrm{F}$ e os testes de médias, ambas ao nível mínimo 5\% e $1 \%$ de probabilidade, foram efetuadas com o auxílio do software SISVAR para Windows, versão 4.0 (FERREIRA, 2000).

\section{Resultados e Discussão}

De acordo com a analise de variância os métodos de irrigação e as coberturas empregadas no experimento exerceram influência na variável número de frutos (NF) a $1 \%$ de probabilidade, pelo teste F.

Enquanto a variável peso médio de frutos (PF) diferiu-se somente na utilização dos métodos de irrigação a $1 \%$ de probabilidade pelo teste $\mathrm{F}$, conforme descrito na Tabela 1. Observa-se ainda, para as variáveis em estudo, que o DBC, a $5 \%$ de probabilidade, não foi significativo, não justificando, portanto, o controle local, ou seja, o delineamento neste caso poderia ser o inteiramente casualizado.

Tabela 1. Análise de variância para número de frutos (NF) e peso médio de frutos (PF), em função diferentes métodos de irrigação e cobertura de solo. Belém-PA.UFRA/ICA- 2005.

\begin{tabular}{cccc}
\hline \multirow{2}{*}{ Fonte de Variação } & \multirow{2}{*}{ G.L. } & \multicolumn{2}{c}{ Q.M. } \\
\cline { 3 - 4 } & & NF (unid.) & PF (kg) \\
\hline Métodos de irrigação & 2 & $29,6944^{* *}$ & $17,1496^{* *}$ \\
Cobertura do solo & 3 & $42,1018^{* *}$ & $0,7192^{\text {ns }}$ \\
Interação (método e cobertura) & 6 & $8,8796^{\text {ns }}$ & $0,1404^{\text {ns }}$ \\
Bloco & 2 & $10,3611^{\text {ns }}$ & $0,2718^{\text {ns }}$ \\
Resíduo & 22 & $4,8156^{\text {ns }}$ & 0,2698 \\
\hline C.V. (\%) & - & 23,87 & 10,12 \\
Média & - & 9,91 & 5,13 \\
\hline
\end{tabular}

ns - não significativo pelo teste $\mathrm{F}$,

* e ** - significativos a 5 e $1 \%$ de probabilidade pelo teste $\mathrm{F}$, respectivamente.

$\mathrm{Na}$ Tabela 2, verifica-se melhores médias de números de frutos e peso médio de frutos quando se utilizou irrigação, tendo os métodos de irrigação por gotejamento e sulcos apresentam médias superiores quando comparadas com a testemunha, concordando assim com Vieira e Manfrinato (1974), Bernardo (1984) e Carvalho (1999), que destacam as vantagens do uso da irrigação por gotejamento e sulco em seus estudos. Para o peso médio de frutos, o método de irrigação por gotejamento se diferiu estatisticamente dos demais tratamentos, sendo este considerado melhor para obtenção de frutos mais pesados.

Devido às inúmeras vantagens da irrigação localizada (gotejamento) em comparação com a irrigação por superfície (sulco), a primeira pode ter obtido vantagem na aplicação de água para a variável peso de frutos, esta por ter proporcionado ao solo uma umidade favorável por um período de tempo maior em decorrência de uma freqüência de irrigação maior.

Martins et al. (1998) obteve produção de 2,57 $\mathrm{kg} /$ planta frutos de melancia trabalhando com dois frutos entre o $8^{\circ}$ e $11^{\circ}$ entre nó da planta. Azevedo et al. (2005) utilizando sistema de irrigação por gotejamento obteve peso médio de frutos entorno de $3 \mathrm{~kg}$ para a variedade Mickylee PVP, sendo esta media inferior a obtida neste trabalho.

Verifica-se na Tabela 3, que as coberturas que proporcionaram maiores números de frutos foram à fibra de coco e a palhada, estas se diferem estatisticamente da cobertura de filme plástico e do solo nu. 
Tabela 2. Número de frutos de melancia e peso médio de frutos de melancia $(\mathrm{kg})$ em função do método de irrigação. Belém-PA. UFRA/ICA.- 2005.

\begin{tabular}{lcc}
\hline Método de Irrigação & Números de Frutos & Peso de Frutos \\
\hline Sem irrigação & $7,83 \mathrm{~b}$ & $3,87 \mathrm{c}$ \\
Irrigação por sulco & $8,83 \mathrm{ba}$ & $5,28 \mathrm{~b}$ \\
Irrigação por gotejamento & $10,92 \mathrm{a}$ & $6,24 \mathrm{a}$ \\
\hline
\end{tabular}

*Médias seguidas da mesma letra, na coluna, não diferem entre si pelo teste de Tukey a $5 \%$ de probabilidade.

Tabela 3. Número de frutos de melancia, em função da cobertura do solo Belém-PA. Belém-PA.UFRA/ICA- 2005.

\begin{tabular}{lc}
\hline Cobertura do Solo & Números de Frutos \\
\hline Sem cobertura & $6,55 \mathrm{c}$ \\
Filme Plástico & $8,77 \mathrm{cb}$ \\
Palhada & $9,66 \mathrm{ba}$ \\
Fibra de coco & $11,77 \mathrm{a}$ \\
\hline
\end{tabular}

*Médias seguidas da mesma letra, na coluna, não diferem entre si pelo teste de Tukey a 5\% de probabilidade.

Araújo (2000), avaliou os efeitos das coberturas do solo com polietileno preto, polietileno dupla face (preto/prateado), e palha de carnaúba sobre o cultivo de melão, não tendo observado diferenças significativas entre os tratamentos para essa característica. No entanto, o peso médio de frutos não se diferiu estatatisticamente quando se utilizou diferentes coberturas neste experimento.

Em solos tropicais, Lal (1974) constatou aumento no rendimento de grãos de milho de 46,52 e $22 \%$ em três anos sucessivos, cultivados sob cobertura morta. A palhada reduz a variação da temperatura do solo, facilitando os processos biológicos e a vida no solo (SATURNINO; LANDERS, 1997), uma vez que os raios solares não incidem diretamente na sua superfície (BALBINO et al., 1996).

O uso da cobertura plástica utilizada neste experimento não se diferiu estatisticamente da testemunha, sendo este resulto contrario dos obtidos por Ininov (1997) e Bhella (1988), respectivamente, para a cultura da melancia.
Segundo Martins (1983) avaliando diferentes matérias como cobertura, concluiu que, a produção da cultura do morangueiro teve uma maior tendência de rendimento quando se utilizou cobertura plástica. Resultados contrários obtiveram-se neste trabalho para a variável número de frutos, destacando-se as coberturas de fibra de coco e palhada para obtenção de maiores valores para essa variável.

$\mathrm{Na}$ Tabela 4, verifica-se um resumo da analise de variância para o diâmetro logitudinal (DL) e diâmetro transversal (DT) dos frutos de melancia. Pela tabela observa-se que os métodos de irrigação exerceram influência a $1 \%$ de probabilidade, pelo teste $\mathrm{F}$, sobre as variáveis analisadas, enquanto a cobertura do solo foi significativa a 5\% somente para a variável diâmetro longitudinal.

Verifica-se na Tabela 5 que os maiores diâmetros foram obtidos com a utilização da irrigação por gotejamento, este tipo de aplicação de água no solo se diferiu estatisticamente dos demais tratamentos. 
Tabela 4. Análise de variância para o diâmetro longitudinal (DL) e diâmetro transversal (DT) do fruto de melancia , em função diferentes métodos de irrigação e cobertura de solo. UFRA, Belém, PA, 2005.

\begin{tabular}{cccc}
\hline Fonte de Variação & \multirow{2}{*}{ G.L. } & \multicolumn{2}{c}{ Q.M. } \\
\cline { 3 - 4 } & & DL (cm) & DT (cm) \\
\hline Métodos de irrigação & 2 & $58,5678^{* *}$ & $34,9260^{* *}$ \\
Cobertura do solo & 3 & $3,8688^{*}$ & $0,8844^{\mathrm{ns}}$ \\
Interação (método e cobertura) & 6 & $1,5824^{\mathrm{ns}}$ & $0,8544^{\mathrm{ns}}$ \\
Bloco & 2 & $1,1457^{\mathrm{ns}}$ & $3,4356^{*}$ \\
Resíduo & 22 & 0,9691 & 0,8842 \\
\hline C.V. (\%) & - & 4,39 & 4,49 \\
Média & - & 22,43 & 20,96 \\
\hline
\end{tabular}

ns - não significativo pelo teste $\mathrm{F}$

$* \mathrm{e}^{* *}$ : significativos a 5 e $1 \%$ de probabilidade pelo teste $\mathrm{F}$, respectivamente.

Tabela 5. Diâmetros, longitudinal e transversal, de frutos de melancia $(\mathrm{cm})$, em função dos métodos de irrigação. Belém-PA.UFRA/ICA- 2005.

\begin{tabular}{ccc}
\hline Método de Irrigação & Diâmetro longitudinal & Diâmetro Transversal \\
\hline Sem irrigação & $20,01 \mathrm{c}$ & $19,09 \mathrm{c}$ \\
Irrigação por sulco & $22,93 \mathrm{~b}$ & $21,34 \mathrm{~b}$ \\
Irrigação por Gotejamento & $24,34 \mathrm{a}$ & $22,44 \mathrm{a}$ \\
\hline
\end{tabular}

*Médias seguidas da mesma letra na coluna, não diferem entre si, pelo teste de Tukey a 5\% de probabilidade.

Avaliando diferentesníveis de irrigaçãonacultura da melancia variedade Mickylee PVP Azevedo et al. (2005) obtiveram comprimento médio de fruto entre $29 \mathrm{~cm}$, sendo este valor superior ao obtido neste trabalho. Os mesmos autores mensuraram a o perímetro de frutos encontrado valor médio de $46 \mathrm{~cm}$.

Observando a Tabela 6, não houve diferença significativa entre as coberturas utilizadas para o diâmetro longitudinal. Pela analise de variância (tabela 4) não se verificou diferença significativa entre as coberturas para o diâmetro transversal dos frutos de melancia.

Passos (1997) relata que as coberturas do solo, tanto as permeáveis com as impermeáveis, têm resultado em maiores produções de morango, em relação ao solo descoberto. Para o experimento em questão, verificou-se diferença somente entre a palhada e a testemunha, tendo a primeira alcançado média superior.

Tabela 6. Médias do diâmetro longitudinal dos frutos de melancia $(\mathrm{cm})$, em função da cobertura do solo. Belém-PA. UFRA/ICA- 2005.

\section{Cobertura do Solo}

Sem cobertura

Filme Plástico

Fibra de coco

Palhada

\section{Diâmetro longitudinal}

$$
\begin{gathered}
21,68 \mathrm{~b} \\
22,09 \mathrm{ab} \\
22,85 \mathrm{ab} \\
23,09 \mathrm{a}
\end{gathered}
$$

* Médias seguidas da mesma letra na coluna, não diferem entre si, pelo teste de Tukey a 5\% de probabilidade. 


\section{Conclusões}

A irrigação por gotejamento proporcionou aumento de produtividade devido aumento de peso médio de frutos, diâmetro logitudinais e transversal.

As coberturas do solo com fibra de côco e palhada produziram maior número de frutos que as coberturas com filme plástico e a testemunha

As coberturas do solo não influenciaram no diâmetro longitudinal de frutos.

\section{Referências}

ARAÚJO, A. P. Cobertura do solo e métodos de plantio no cultivo do melão amarelo. 2000. Dissertação (Mestrado em Fitotecnia) - Universidade Federal Rural do SemiÁrido, Mossoró.

AZEVEDO, B. M.; BASTOS, F. G. C.; VIANA, T. V. A.; RÊGO, J. L.; ÁVILA, J. H. T. Efeitos de níveis de irrigação na cultura da melancia. Revista Ciência Agronômica, Fortaleza, v. 36, n. 1, p. 9-15. jan-abr., 2005.

BALBINO, L. C.; MOREIRA, J. A. A.; SILVA, J. G.; OLIVEIRA, E. F.; OLIVEIRA, I. P. Plantio direto. In: ARAUJO, R. S.; RAVA, C. A.; STONE, L. F.; ZIMMERMANN, M. J. O. Cultura do feijoeiro comum no Brasil. Piracicaba: Potafós, 1996. p. 301-352.

BERGAMASCHI, H.; BERLATO, M. A.; MATZENAUER, R.;FONTANA,D.C.Agrometereologia aplicada à irrigação. Porto Alegre: EDUFRGS, 1992.

BERNARDO, S. Manual de irrigação. Viçosa: Imprensa Universitária, 1984.

BHELLA, H. S. Effect of trickle irrigation and black mulch on growth, yield, and mineral composition of watermelon. Hortscience, Alexandria, v. 23, n. 1 p. 123-5, Feb. 1988.

CARVALHO, R. N. Cultivo de melancia para agricultura familiar. Brasília: Embrapa-SP, 1999.

DOORENBOS, J.; PRUITT, W. O. Guidelines for predictings crop water requirements. Roma: FAO, 1977. (Irrigation and Drainage Paper, 24).
FERREIRA, D. F. Análises estatísticas por meio do Sisvar para Windows versão 4.0. In: REUNIÃO ANUAL DA REGIÃO BRASILEIRA DA SOCIEDADE INTERNACIONAL DE BIOMETRIA, 45., 2000, São Carlos, SP. Anais... São Carlos: Sociedade Internacional de Biometria, 2000. p. 255 - 258.

ININOV, B. Watermelon and muskmelon growing under polyethylene film mulch Gradinarstvo, Bulgaria. Horticultural Abstracts, Farnhan Royal, v. 47, n. 4, p. 315, abst.3602, apr. 1997.

LAL, R. Soil temperature, soil moisture and maize yield from mulched and unmulched tropical soil. Plant and Soil, The Hague, v. 40, n. 1, p. 129-143, Feb.1974.

LIAKATAS, A.; CLARK, J. A.; MONTEITH, J. L. Measurements of the heat balance under plastic mulches. Agricultural and Forest Meteorology, Amsterdam, v. 36, n. 3, p. 227-39, 1986.

MARTINS, N. L. F. Efeitos de coberturas plásticas e orgânicas sobre o rendimento de frutos de duas cultivares de morangueiro (Fragaria x ananassa Duch.) e a temperatura do solo. 1983. Dissertação (Mestrado) Faculdade de Agronomia, Universidade Federal do Rio Grande do Sul, Porto Alegre.

MARTINS, S. R.; PEIL, R. M.; SCHWENGBER, J. E.; ASSIS, F. N.; MENDEZ, M. E. G. Produção de melão em função de diferentes sistemas de condução de plantas em ambiente protegido. Horticultura Brasileira, Brasília, v. 16, n. 1, p. 24-30, 1998.

MULLER, A. G. Comportamento térmico do solo e do ar em alface (Lactuca sativa.) para diferentes tipos de cobertura do solo. 1991. Dissertação (Mestrado) - Escola Superior de Agricultura "Luiz de Queiroz", Universidade de São Paulo, Piracicaba.

PASSOS, F. A. Influência de alguns sistemas de cultivo na cultura do marango (Fragaria x ananassa Duch.). 1997. Tese (Doutorado) - Escola Superior de Agricultura "Luiz de Queiroz”, Universidade de São Paulo, Piracicaba.

REICHARDT, K. A água na produção agrícola. São Paulo: McGraw-Hill do Brasil, 1978.

SATURNINO, H. M.; LANDERS, J. N. Introdução. In: O meio ambiente e o plantil direto. Brasília: EMBRAPASPI, 1997. p.13.

VIEIRA, D. B.; MANFRINATO, H. A. A irrigação por gotejamento em berinjela (solanum melongela L.). Anais da ESALQ, Piracicaba, v. 31, p. 72-90. 1974. 
